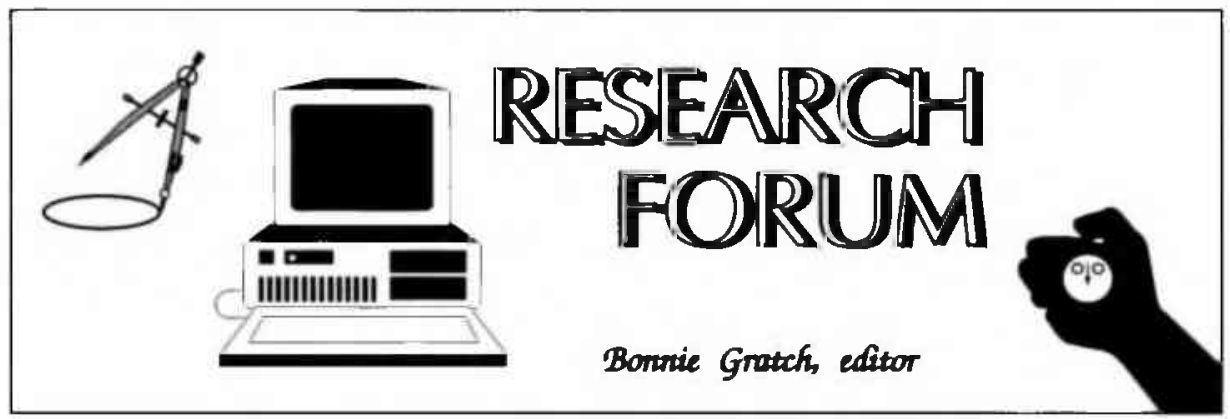

\title{
4 Impact of NTIS CD-ROM on the use of a technical report collection
}

\author{
By Linda R. Musser \\ Head, Earth and Mineral Sciences \\ Library \\ Pennsylvania State University
}

Low use of library materials has always been an area of concern for librarians, from the standpoint of costs for acquisition and maintenance as well as concern for fulfilling the user's information needs. It has been theorized that one of the reasons for low use is lack of easy access to the material by the user. Prior to the advent of electronic resources, however, this premise was difficult to prove. The ability to improve access to information has been one of the major justifications behind decisions to invest in electronic resources such as CD-ROM indexes. These CD-ROM products are particularly exciting because the relatively simple command structure allows users to begin retrieving useful results almost immediately, and there is usually no charge for the information. While there is no doubt that CD-ROM products are popular with users, how they affect access is not as obvious. This paper summarizes the results of a study that examined the influence of the NTIS CD-ROM on the use of a technical report collection.

Technical reports are an important component of the scientific literature, and access to these materials is vital at a research university. Traditionally, however, technical reports have not been highly used by university researchers. Easy access to these materials has always been lacking. Technical reports are rarely, if ever, provided the same access in the library catalog as journals, books, or even government documents.

\author{
and Thomas W. Conkling \\ Head, Engineering Library \\ Pennsylvania State University
}

The Engineering Library at the Pennsylvania State University maintains a large collection of technical reports in a variety of formats and actively encourages their use. Currently the library receives microfiche copies of technical reports in preselected subject categories via the GPO and NASA depository programs as well as the Selected Research in Microfiche (SRIM) program of NTIS. These programs are supplemented by an on-demand ordering program for titles not included in the collection. Selected paper copies of technical reports are also received directly from various organizations. As of January 1990, the Engineering Library's collection of technical reports contained approximately 240,000 items and had a growth rate of 35,000 per year.

Prior to the introduction of the NTIS CD-ROM, indexed access to the technical report collection was provided by several tools, including Government Reports Announcements and Index (the paper equivalent of NTIS), Scientific and Technical Aerospace Reports, International Aerospace Abstracts, Energy Research Abstracts, and miscellaneous specialized subject bibliographies derived from these tools.

The NTIS CD-ROM was installed in the Engineering Library in September 1989. During this month and the following one, the system was tested, minor problems were corrected, documentation was developed, and staff were introduced to 
the system. A great deal of publicity was not generated to announce the acquisition of the NTIS CDROM. It was mentioned along with other available tools in the regular course-related instruction seminars, and handouts were revised to mention its availability.

In general, the users of the Engineering Library required very little assistance in using the $\mathrm{CD}$ ROM. The majority of users were students, but representatives of all user groups were observed using the system. While users had the option to download their search results to a diskette, most chose to have results printed out. Abuse of printing privileges was generally not a problem.

The effect of the NTIS CD-ROM on the use of the technical report collection was immediate and dramatic. Prior to the advent of the CD-ROM, technical report use was fairly stable. In the first six months of full operation, November 1989 through April 1990, the use of microfiche technical reports increased from the average of 586 for that period in previous years to 1,658 , an increase of $183 \%$. The use statistics were collected monthly from refiling statistics and were broken down by major report series, all of which showed significant increases in use (see graph below).

Other areas of library operations were also impacted to varying degrees by the NTIS CD-ROM. The demand for portable microfiche readers in- creased. Of the five portable readers available, one was always charged out; many times all were. The on-demand ordering program showed an increase in use, and photocopying (micro to paper) increased by $17 \%$ over the same period in the previous year, from 5,718 copies to 6,689 copies.

The results of this study seem to demonstrate that the use of a collection is a function of the ease of access to the materials in that collection. The presence of the CD-ROM in the library has stimulated interest in the technical report collection and has had a positive effect on the users' perception of these materials. Previously, technical reports were an acceptable source of information; with the CDROM available, technical reports have become a favored resource.

If there is a drawback to the CD-ROM, it lies in the fact that it tends to distract users from other information resources, such as journal articles, that might be more appropriate for the work at hand. This is particularly true for undergraduates, who have a tendency to rely on the resource that gives them the most results in the shortest time. To counteract this tendency and provide a more balanced access to the engineering literature as a whole, users are regularly reminded of other information sources, and another CD-ROM covering journal articles is being added to the library.

The effect of the NTIS CD-ROM on technical report use

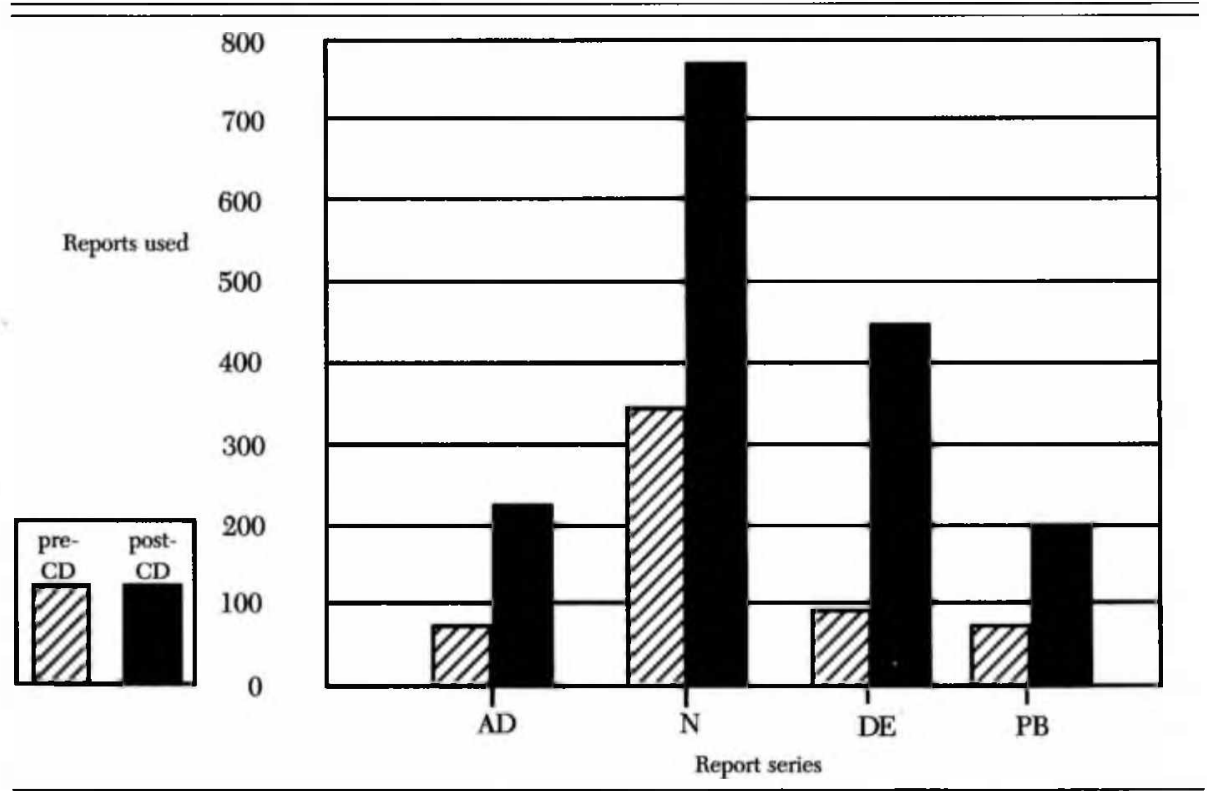

The report series codes correspond to government agency sponsors, as follows: $A D=D e p t$. of Defense, $N=N A S A, D E=$ Dept. of Energy, and $P B=$ miscellaneous government agencies or others. 